\title{
Effect of Phase Transformation During Long-Term Solution Treatment on Microstructure, Mechanical Properties, and Bio-corrosion Behavior of Mg-5Zn-1.5Y Cast Alloy
}

\author{
H. Jafari ${ }^{1} \cdot$ E. Heidari ${ }^{1} \cdot$ A. Barabi ${ }^{1} \cdot$ M. Dashti Kheirabadi ${ }^{1}$ \\ Received: 29 September 2017 / Revised: 18 November 2017 / Published online: 6 February 2018 \\ (c) The Chinese Society for Metals and Springer-Verlag GmbH Germany, part of Springer Nature 2018
}

\begin{abstract}
The influence of long-term solution treatment for various intervals on the microstructure, mechanical properties, and corrosion resistance of the as-cast $\mathrm{Mg}-5 \mathrm{Zn}-1.5 \mathrm{Y}$ alloy was investigated. Variation of secondary phases was studied during solution treatment through thermal analysis test and thermodynamic calculations. Tensile and hardness tests, as well as polarization and immersion tests, were performed to evaluate the mechanical properties and corrosion behavior of the ascast and heat-treated alloy, respectively. Results show that solution treatment transforms I-phase $\left(\mathrm{Mg}_{3} \mathrm{Zn}_{6} \mathrm{Y}\right)$ into W-phase $\left(\mathrm{Mg}_{3} \mathrm{Zn}_{3} \mathrm{Y}_{2}\right)$, as well as dissolves it into the $\alpha$-Mg matrix to some extent; therefore, the amount of $\mathrm{W}$-phase increases. Moreover, prolonged solution treatment decreases the volume fraction of the phases. In the first stage of solution treatment for $14 \mathrm{~h}$, the tensile properties significantly increase due to the incomplete phase transformation. Although long-term solution treatment sharply decreases the tensile and hardness properties of the alloy, it improves the corrosion resistance due to the transformation of I-phase into W-phase. In fact, it decreases corrosion potential and simultaneously dissolves intermetallic compounds into the $\alpha-\mathrm{Mg}$ matrix, resulting in the reduction in galvanic microcells between the matrix and compounds. It is found that the optimum time for long-term solution treatment is $14 \mathrm{~h}$, which improves both corrosion behavior and mechanical properties.
\end{abstract}

Keywords Magnesium alloy $\cdot$ Long-term solution treatment $\cdot$ Microstructure $\cdot$ Mechanical properties $\cdot$ Bio-corrosion

\section{Introduction}

Magnesium alloys have been attracted extensive attention recently in industrial and biomedical applications because of their low density, favorable machinability, and recycling capability $[1,2]$. However, low strength, poor ductility, and corrosion resistance limit the applications of the alloys. Magnesium and its alloys are characterized as the suitable candidates for biocompatible implants due to their degradation and absorption in the human body to meet the important requirements of modern orthopedic surgery [3]. Therefore, various binary, ternary, and quaternary alloys of

Available online at http://link.springer.com/journal/40195

H. Jafari

hjafari@srttu.edu

1 Materials Engineering Department, Faculty of Materials Engineering and Modern Technologies, Shahid Rajaee Teacher Training University, Tehran 16785-136, Iran magnesium, such as AZ, AM, WE, ZK, ZW, ZEK, have been developed [4, 5]. Recently, the research and development activities on $\mathrm{Mg}-\mathrm{Zn}-\mathrm{Y}$ alloys have significantly increased because of their superior mechanical properties, arising from the formation of different ternary phases [6,7], which makes these alloys as one of the notable candidates for biodegradable applications [8]. The microstructure of $\mathrm{Mg}-\mathrm{Zn}-\mathrm{Y}$ alloys usually consists of $\alpha-\mathrm{Mg}$ matrix and intermetallic compounds, namely I-phase $\left(\mathrm{Mg}_{3} \mathrm{Zn}_{6} \mathrm{Y}\right)$, W-phase $\left(\mathrm{Mg}_{3} \mathrm{Zn}_{3} \mathrm{Y}_{2}\right)$, and LPSO-phase ( $\mathrm{Mg}_{12} \mathrm{ZnY}$; LPSO: long-period stacking order) [9-12]. Several studies have shown that the ratio of $\mathrm{Zn} / \mathrm{Y}$ affects phase formation in $\mathrm{Mg}-$ $\mathrm{Zn}-\mathrm{Y}$ alloys [13, 14], with a ratio of 4.38 and the microstructure of the alloy consists of I-phase in $\alpha-\mathrm{Mg}$ matrix. W-phase would increasingly develop by decreasing the ratio since the quantity of $\mathrm{Zn}$ will no longer be adequate to fully form I-phase [14]. In addition, as W-phase has a face-centered cubic crystal structure which has a weak bonding with $\alpha-\mathrm{Mg}$ matrix, it has a deleterious effect on the strength of these alloys $[13,15,16]$. However, I-phase with 
an icosahedral quasicrystal structure has favorable characteristics such as high hardness, thermal stability, and corrosion resistance, as well as the low coefficient of friction and interfacial energy [17-19]. Therefore, mechanical properties of the ternary $\mathrm{Mg}-\mathrm{Zn}-\mathrm{Y}$ alloys with formation of I-phase can be improved [20, 21]. In contrast, although $\mathrm{W}$-phase decreases the strength, it has a highly toughening effect than I-phase [8, 16]. It is worth mentioning that I-phase would transform into $\mathrm{W}$-phase during heating at around $400{ }^{\circ} \mathrm{C}$, and this transformation may affect the alloy mechanical properties and corrosion resistance [22, 23]. Furthermore, the addition of RE elements can improve the corrosion resistance and mechanical properties [24]. It has also been shown that a passive $\left(\mathrm{Y}_{2} \mathrm{O}_{3}\right)$ film forms on the surface of $\mathrm{Mg}-\mathrm{Zn}-\mathrm{Y}$ alloy due to the low cathodic current density [25]. Jafari et al. [26] confirmed an influential impact of yttrium on the corrosion resistance of $\mathrm{Mg}-5 \mathrm{Zn}$ alloy, and a low corrosion rate of 0.7 in simulated body fluid (SBF) for $\mathrm{Mg}-5 \mathrm{Zn}-1.5 \mathrm{Y}$ alloy was reported. However, the presence of the second phases in the matrix, depending on their different electrochemical potential, causes micro-galvanic corrosion to occur and enhances corrosion rate. Zhang et al. [8] reported that the $\mathrm{Mg}-\mathrm{Zn}-\mathrm{Y}$ alloys with single secondary phase exhibited a better corrosion resistance than the alloys with two secondary phases. He and Yang [27] showed that $\mathrm{W}$-phase has higher electrochemical potential in comparison with I-phase and as a result, I-phase has higher corrosion rate. Therefore, considering the secondary phases existing in the $\mathrm{Mg}-\mathrm{Zn}-\mathrm{Y}$ alloys, heat treatment is a beneficial way to improve both corrosion and mechanical properties of magnesium alloys [28]. Consequently, heat treatment of $\mathrm{Mg}-\mathrm{Zn}-\mathrm{Y}$ alloys containing two secondary phases may result in dissolving the phases in the matrix and simultaneously may transform I-phase into W-phase, improving the corrosion resistance of the alloy. Therefore, controlling the formation and dissolution of secondary phases to balance the mechanical properties and corrosion resistance for biomedical applications is a challenging issue.

The aim of this study is to improve both mechanical and corrosion properties of the $\mathrm{Mg}-5 \mathrm{Zn}-1.5 \mathrm{Y}$ alloy by longterm solution treatment in a temperature range in which transformation of I-phase into $\mathrm{W}$-phase occurs and to find an optimum time for the solution treatment, leading to improved mechanical and corrosion properties.

\section{Experimental}

\subsection{Materials and Alloy Preparation}

Commercially high-purity ingots of magnesium (99.9\%) and zinc (99.9\%), and $\mathrm{Mg}-30 \% \mathrm{Y}$ master alloy were used to make the $\mathrm{Mg}-5 \mathrm{Zn}-1.5 \mathrm{Y}$ alloy. The alloy was melted using an induction furnace (Azar furnace, VM10L1200) in a steel crucible under the protective gas of pure argon. Zinc was first added to molten magnesium at $730{ }^{\circ} \mathrm{C}$. Then, the master alloy was added to the molten alloy while it was being stirred to prevent undissolved $\mathrm{Y}$ in the as-cast alloy. The molten alloy was cast into a steel mold preheated to $350{ }^{\circ} \mathrm{C}$, and the schematic illustration of the mold is shown in Fig. 1.

\subsection{Thermal Analysis}

Thermal analysis was run to determine the characteristic temperatures of the alloy during cooling and solidification to ensure an appropriate selection of a temperature for the subsequent long-term solution treatment of the cast alloy. The prepared molten metal was poured at $730{ }^{\circ} \mathrm{C}$ into a stainless steel cup preheated to $350{ }^{\circ} \mathrm{C}$ while a K-type thermocouple had been set at its center. The temperaturetime data were recorded during cooling the molten metal to room temperature. The temperature-time data were recorded during cooling the molten metal using a data logger. Cooling and the corresponding first derivation curves were plotted by FlexPro software (Version 8.01). The analysis was repeated three times to ensure reliability of the results.

\subsection{Long-Term Solution Treatment}

The specimens were cut from the cast samples and heated at $415{ }^{\circ} \mathrm{C}$ for different time periods of $6,14,24,36$, and $50 \mathrm{~h}$ followed by water quenching.

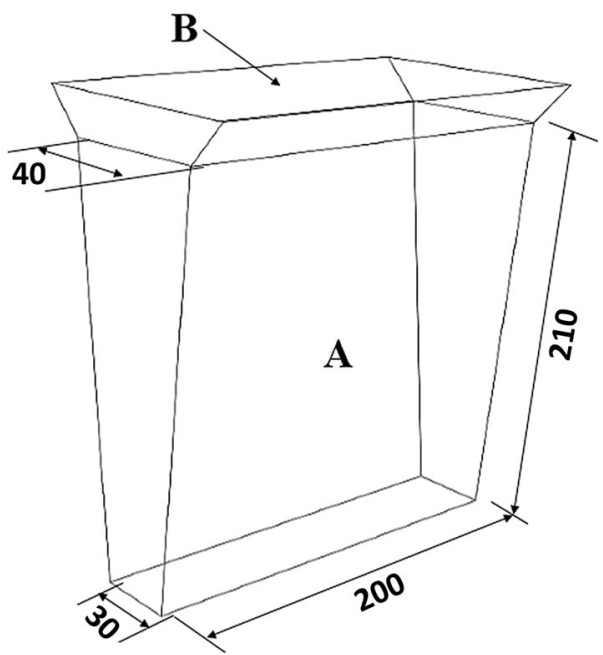

Fig. 1 Schematic illustration of steel mold (A: cavity, $B$ : pouring basin; unit: $\mathrm{mm}$ ) 


\subsection{Microstructure Characterization}

The specimens were ground with $\mathrm{SiC}$ papers up to a final 5000 grit and mechanically polished with $7-\mu \mathrm{m}$-sized diamond paste followed by etching with $6 \%$ Nital. An optical microscope (OM, Meiji Techno CO-ML 7000) and scanning electron microscope (SEM, Tescan Vega 3) equipped with an energy dispersive spectroscopy (EDS) detector were used to characterize the microstructure of the as-cast and solution-treated alloy. X-ray diffraction (XRD, Philips $\mathrm{Xpert} \mathrm{Cu}-K \alpha$ mode) analysis was carried out to evaluate the phase changes during long-term solution treatments. Thermodynamic calculations were done using Jmat Pro 7 software to predict the presence of phases at room temperature as well as at $415^{\circ} \mathrm{C}$. In addition, Clemex image analysis software was used to quantify the volume percentage of secondary phases in the microstructure.

\subsection{Mechanical Properties}

Tensile test samples were prepared according to ASTMB557 standard with the gage length and diameter of 35 and $9 \mathrm{~mm}$, respectively. The test was performed using a Zwick/ Roell Z150 universal testing machine with the same strain rate of $0.001 \mathrm{~s}^{-1}$. Brinell hardness test was performed using an Ernest machine with a 5-mm-diameter steel ball indenter under a force of $125 \mathrm{~N}$. A minimum of six readings and three tests were carried out for the hardness and tensile measurements to obtain reliable results.

\subsection{In Vitro Degradation Evaluation}

Polarization and immersion tests were carried out in simulated body fluid (SBF) to evaluate the corrosion behavior and biodegradability of the as-cast and solution-treated alloy. The chemical materials and preparing method of SBF have been explained in Ref. [26].

The polarization test was performed using a potentiostat (SAMA 500 Electro Analyzer system) linked to a computer. The scanning rate of $0.5 \mathrm{mV} \mathrm{s}^{-1}$ and potential range of 1.25-2.00 V were selected for the test. A standard threeelectrode cell, containing $40 \mathrm{ml} \mathrm{SBF}$ with the temperature and $\mathrm{pH}$ of $37^{\circ} \mathrm{C}$ and 7.4 , respectively, consists of a reference electrode (standard calomel electrode, SCE), a counter electrode (platinum rod), and a working electrode (the specimen), was used to measure the electrochemical behavior of the as-cast and solution-treated alloy. Before starting the test, the specimen was soaked in SBF for $2 \mathrm{~min}$ to measure the electrochemical parameters more precisely, and to provide uniform test conditions for all specimens. Corrosion rate $\left(\mathrm{CR}, \mathrm{mm} \mathrm{y}^{-1}\right)$ of the specimens was calculated after conducting the test and extracting $i_{\text {corr }}$ $\left(\mathrm{A} \mathrm{cm}^{-2}\right.$ ) as follows:

$\mathrm{CR}=2.285 \times 10^{4} \times i_{\text {corr }}$.

In order to complement the degradation evaluation, immersion test was carried out according to ASTM G31-72 standard. The surface of the specimens was ground using $\mathrm{SiC}$ papers up to 2000 grit prior to the test. Then, each specimen was immersed in a beaker, containing $100 \mathrm{ml}$ $\mathrm{SBF}$, for $144 \mathrm{~h}$. The weight loss was measured every $24 \mathrm{~h}$ by removing the specimen from the SBF, soaking it in the chromic acid solution for cleansing the corrosion product, drying, and then weighing with a \pm 0.0001 accuracy balance (OHAS Adventure). $\mathrm{pH}$ of the SBF was also measured at the same intervals with a pH meter (Mi180 Bench Meter Martini instrument). SEM/EDS and XRD analyses were carried out to investigate the morphology and composition of the corrosion products.

\section{Results and Discussion}

\subsection{Thermal Analysis and Thermodynamic Calculations}

Lee et al. [29] reported that the phase formation in the ascast $\mathrm{Mg}-\mathrm{Zn}-\mathrm{Y}$ alloys depends on the $\mathrm{Zn} / \mathrm{Y}$ ratio. It is believed that $\mathrm{I}-$ and $\mathrm{W}$-phases are formed if the ratio is about 5-7 and 1.5-2, respectively [29-31]. Therefore, with the $\mathrm{Zn} / \mathrm{Y}$ ratio of about $2-4$, both $\mathrm{I}-$ and $\mathrm{W}$-phases are present in the alloy $[9,10,32]$. Considering the $\mathrm{Zn} / \mathrm{Y}$ ratio of about 3.3 for the present alloy, $\mathrm{Mg}-5 \mathrm{Zn}-1.5 \mathrm{Y}$, both Iand $\mathrm{W}$-phases are expected.

Figure 2 shows the cooling and corresponding first derivative curves of the as-cast alloy. Three notable peaks

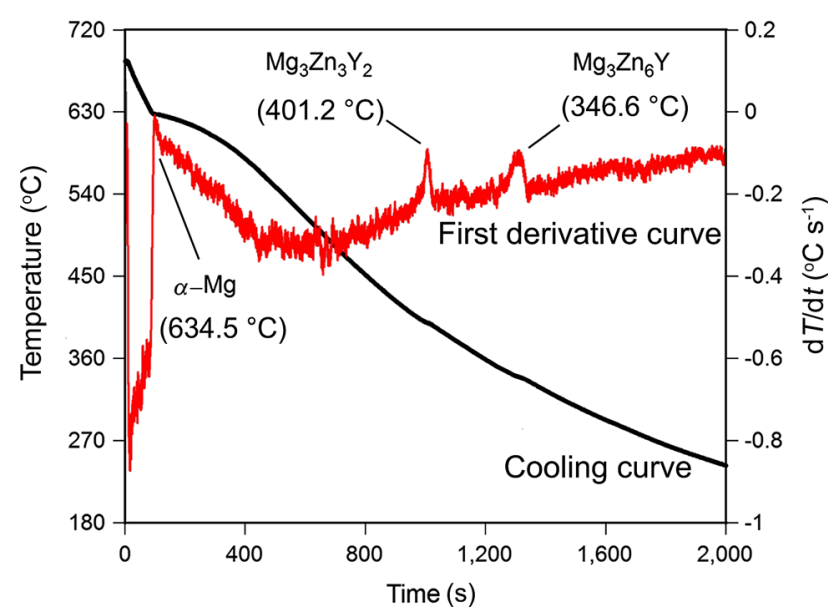

Fig. 2 Cooling and corresponding first derivative curves of $\mathrm{Mg}-5 \mathrm{Zn}-$ $1.5 \mathrm{Y}$ alloy ( $T$ temperature, $t$ time) 
corresponding to the formation of $\alpha-\mathrm{Mg}$ and two intermetallic phases of I- and W-phases at 634.5, 401.2, and $346.6{ }^{\circ} \mathrm{C}$, respectively, can be denoted. Considering the solution temperature $\left(415{ }^{\circ} \mathrm{C}\right)$ in the present research, which is closer to the formation temperature of W-phase, it can be anticipated that a remarkable transformation of I-phase into W-phase, as well as some changes in W-phase, is inevitable during long-term solution treatment.

Figure 3a graphically illustrates the weight percentage and stability of the phases of the investigated alloy as a function of temperature. It is depicted based on the equilibrium thermodynamic prediction using the JMatPro software. It clearly shows that no considerable changes are detected in the contents of $\alpha-\mathrm{Mg}, \mathrm{I}$, and $\mathrm{W}$ when the temperature elevates from the ambient temperature to $318.5^{\circ} \mathrm{C}$. Further increase in the temperature to $400{ }^{\circ} \mathrm{C}$ accelerates the rate of I-phase reduction, resulting in increase in $\mathrm{W}$-phase as well as $\alpha-\mathrm{Mg}$ matrix amounts. This behavior continues up to $468{ }^{\circ} \mathrm{C}$ at which majority of I-phase transforms into W-phase, and some are dissolved, leading to the increase in the amounts of $\alpha-\mathrm{Mg}$. The difference between the above characteristic temperatures obtained from the thermal analysis and thermodynamic calculations is surely attributed to the solidification conditions and nonequilibrium solidification.

Therefore, it is expected that the long-term solution treatment at $415{ }^{\circ} \mathrm{C}$ reduces the accumulative amount of intermetallic phases $(\mathrm{I}+\mathrm{W})$, although the amount of $\mathrm{W}$-phase increases due to the transformation of some percentage of I-phase into W-phase. In order to obtain more detailed information, the weight percentages of all phases at 25 and $415{ }^{\circ} \mathrm{C}$ were calculated, as illustrated in Fig. 3b, c, respectively. The graphs also reveal that the amounts of I- and W-phases are calculated to be 4.83 and $2.51 \mathrm{wt} \%$ (Fig. 3b) as well as 1.75 and 4.17 wt\% (Fig. 3c) when the temperature increases from 25 to $415{ }^{\circ} \mathrm{C}$, respectively. According to the thermal analysis and thermodynamic calculations, $415{ }^{\circ} \mathrm{C}$ is selected as the temperature for long-term solution treatment.

\subsection{Microstructural Evolution}

Figure 4 shows the OM, SEM images and EDS analysis of the as-cast alloy. The OM image (Fig. 4a) discloses that the cast alloy includes a fully equiaxed dendritic $\alpha-\mathrm{Mg}$ grain structure. The SEM image shown in Fig. $4 \mathrm{~b}$ clearly reveals the lamellar structure of eutectic phase (denoted as A) and an intermetallic phase (denoted as B) formed at the grain boundaries. The lamellar morphology is identified as $\alpha$ $\mathrm{Mg}+\mathrm{I}$-phase pockets [33]. The accumulation of alloying elements at the above-mentioned positions during solidification, which is due to the low solid solubility of $\mathrm{Zn}$ and especially $\mathrm{Y}$, is the reason for the formation of such phases as the evidence of segregation phenomenon.

The EDS analysis of point A shown in Fig. 4c indicates the presence of I-phase with a $\mathrm{Zn} / \mathrm{Y}$ ratio of 5.24, while the analysis of point B (Fig. 4d) shows the formation of $\mathrm{W}$-phase with a $\mathrm{Zn} / \mathrm{Y}$ ratio of 1.9 . The results are in good agreement with those reported by Zhang et al. [8].

Figure 5 shows OM images of the heat-treated specimens. As seen in Fig. 5a-e, which corresponds to the specimens solution treated for $6-50 \mathrm{~h}$, respectively, it can be inferred that prolonged heating leads to a more homogenized microstructure by dissolving the intermetallic compounds into the matrix.

In other words, increasing solution treatment time decreases the volume fractions of I- and W-phases and the undissolved phases become more dispersed in comparison with the as-cast state. Moreover, I- and W-phases disappear gradually and partially dissolve in the $\alpha-\mathrm{Mg}$ matrix (Fig. 5e), leading to a supersaturated matrix with zinc and yttrium after $50 \mathrm{~h}$ heating. The precise quantitative measurement of the volume fraction of the precipitates made by Clemex image analysis software suggests a consistent result with the OM images (Fig. 5).

Figure 6 demonstrates the results of the image analysis measurements conducted on $\mathrm{OM}$ images. It indicates a continuous uniform trend in decreasing the volume fraction of intermetallic phases with long-term solution treatment. In other words, the volume fraction of the intermetallic (a)

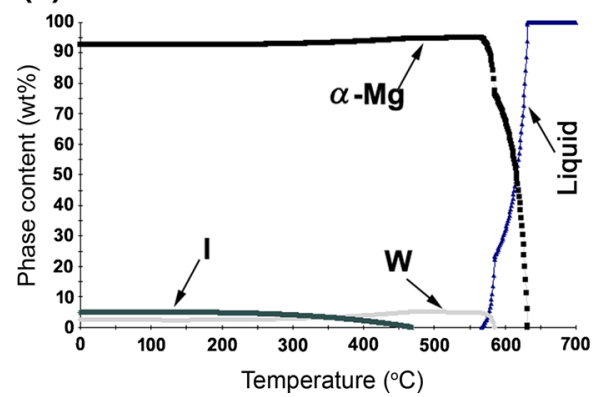

(b)

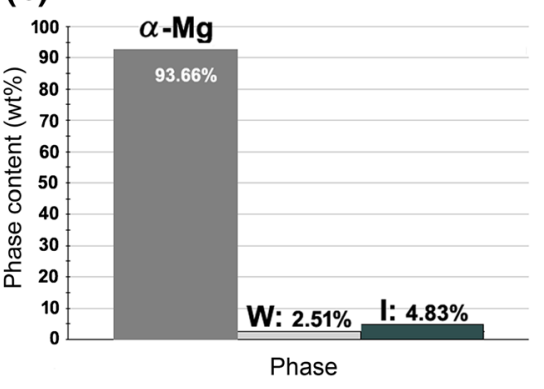

(c)

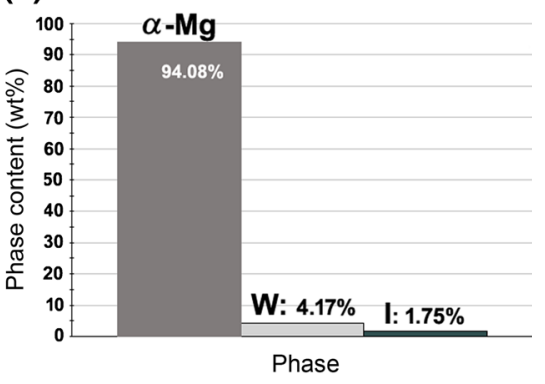

Fig. 3 Thermodynamical predictions of weight percentage of phases in alloys as a function of temperature $\mathbf{a}$, at $25^{\circ} \mathrm{C} \mathbf{b}, 415^{\circ} \mathrm{C} \mathbf{c}$ 

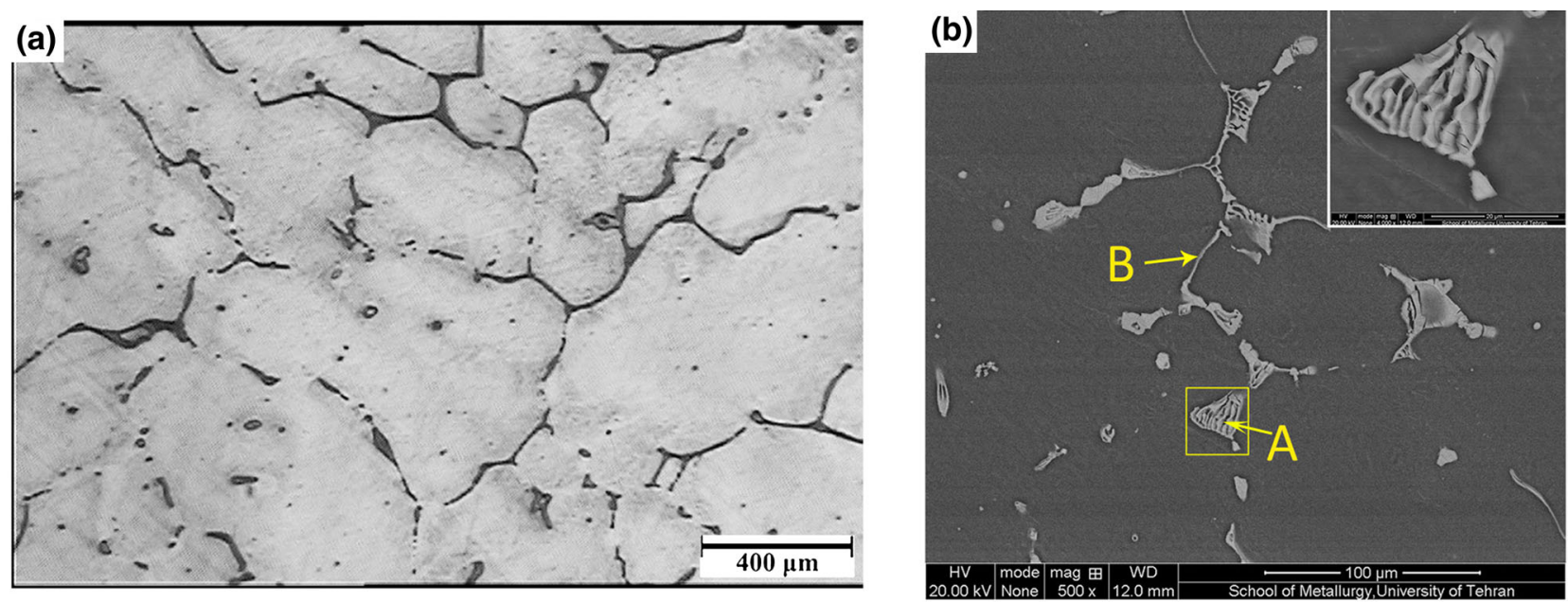

(c)

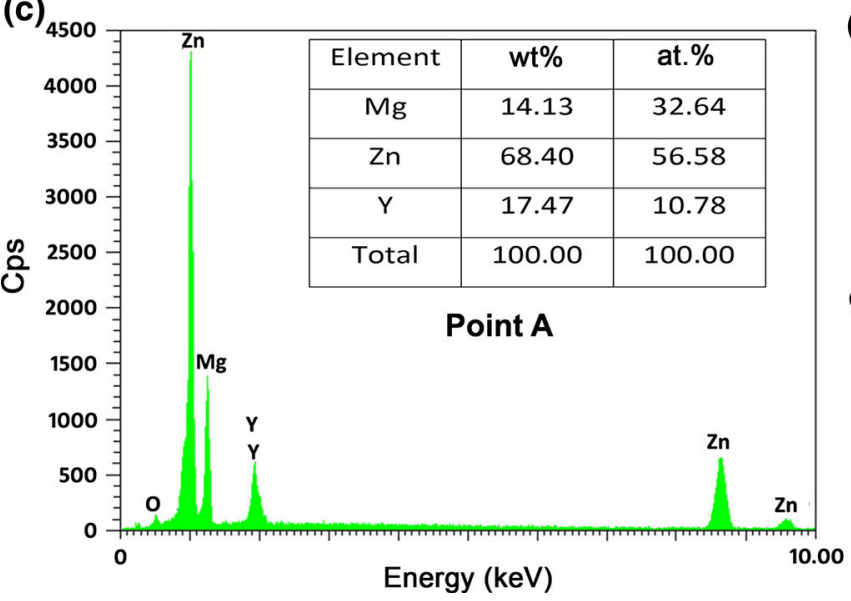

(d)

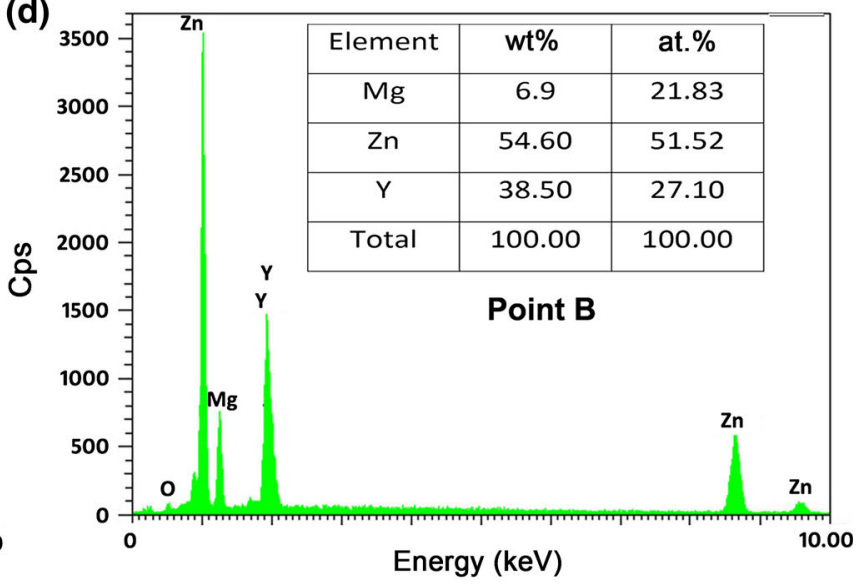

Fig. 4 OM a, SEM $\mathbf{b}$ images of as-cast alloys and EDS analysis of points denoted as A c, B d in Fig. 4b

phases decreases from about 7.17 to $1.55 \%$ (calculating over $78 \%$ ) after $50 \mathrm{~h}$ solution treatment, which seems logic when considering the corresponding optical micrographs in Fig. 5.

Figure 7a, $\mathrm{b}$ shows SEM micrographs of the alloy after heat treatment for 14 and $36 \mathrm{~h}$, respectively. Comparing the micrographs with the one shown in Fig. $4 \mathrm{~b}$, it is claimed that increasing solution time results in a gradual decrease in dimension and volume fraction of the intermetallic phases.

Figure 8 presents the XRD patterns of the as-cast and heat-treated specimens for 14 and $36 \mathrm{~h}$. Interpretation of the peaks revealed that the microstructure of all specimens consists of three phases, $\alpha-\mathrm{Mg}$, I- and W-phases. But as it is evident, the intensity of $\mathrm{W}$-phase increases by increasing solution treatment time. This indicates that increasing the fraction of $\mathrm{W}$-phase and decreasing the fraction of I-phase are attributed to the occurrence of phase transformation and solution of secondary phases simultaneously. Therefore, the results not only confirm the EDS analysis but also reveal that even after heat treatment for $36 \mathrm{~h}$, I- and
W-phases still exist in the alloys, though the volume fraction of the phases is reduced. Remaining intermetallic compounds after such heating may be attributed to the solubility limit of the phases in the matrix at the heating temperature. XRD analysis shows the incomplete solution of secondary phases and occurrence of phase transformation of I-phase into W-phase. Transformation of I-phase into $\mathrm{W}$-phase is a diffusional process and depends upon temperature. I-phase is a $\mathrm{Zn}$-rich phase and makes $\mathrm{Zn}$ concentration gradient to change in between the I-phase and matrix. The ejection of zinc from the I-phase to the matrix, due to the gradient in the concentration, would occur. Therefore, redistribution of elements would occur during phase transformation and an expansion in crystal lattice would happen, causing the icosahedral crystal system to be unstable when the temperature rises [22].

It has been reported that I-phase forms in a eutectic network structure having a lamellar morphology during solidification and can mostly be observed at the triple junctions [11, 34]. Yang et al. [16] reported that W-phase has a needle-shaped morphology and frequently embeds at 

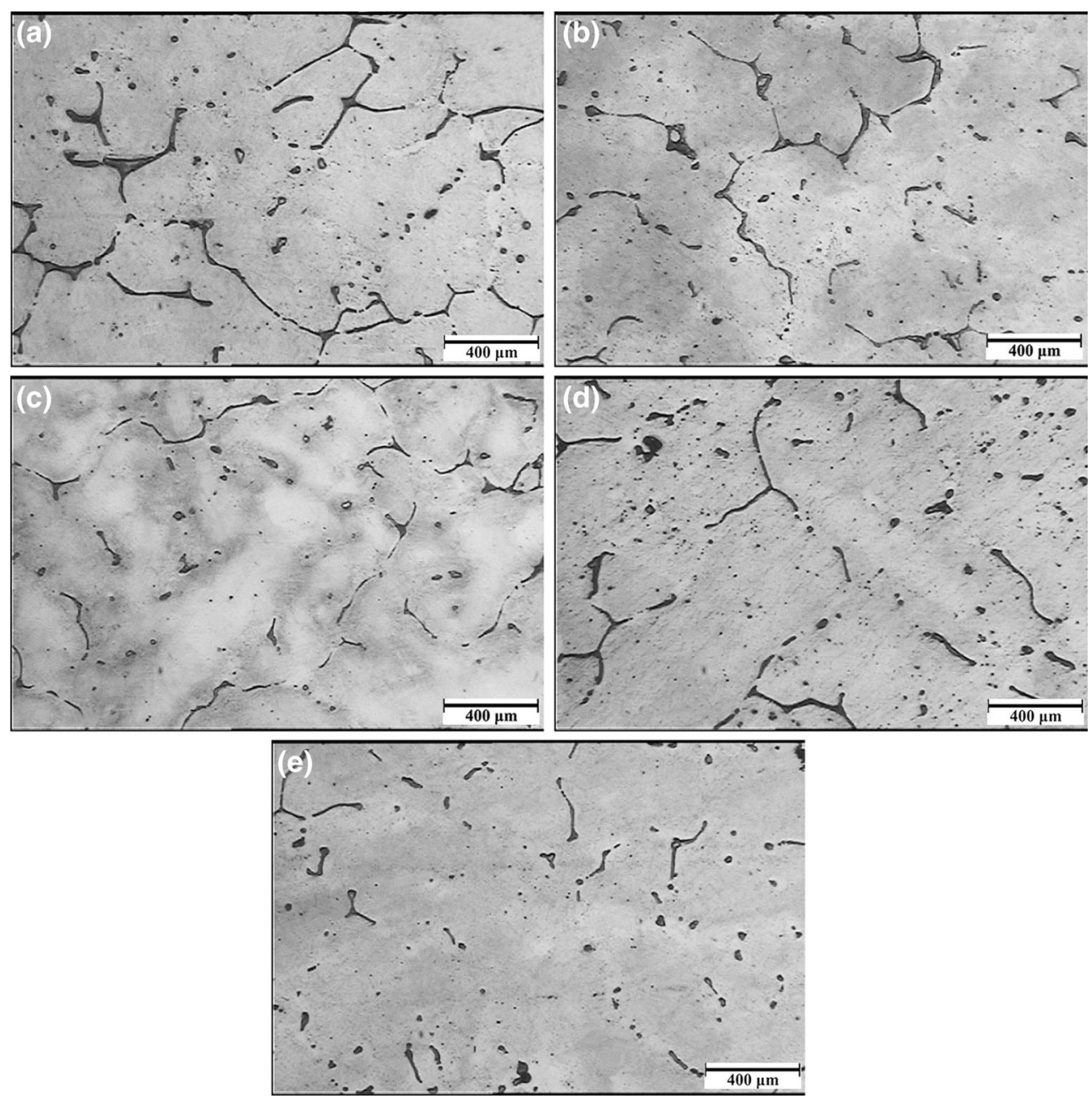

Fig. $5 \mathrm{OM}$ images of alloys after heat treatment for $6 \mathrm{~h} \mathbf{a}, 14 \mathrm{~h} \mathrm{~b}, 24 \mathbf{c}, 36 \mathrm{~h} \mathrm{~d}, 50 \mathrm{~h}$ e

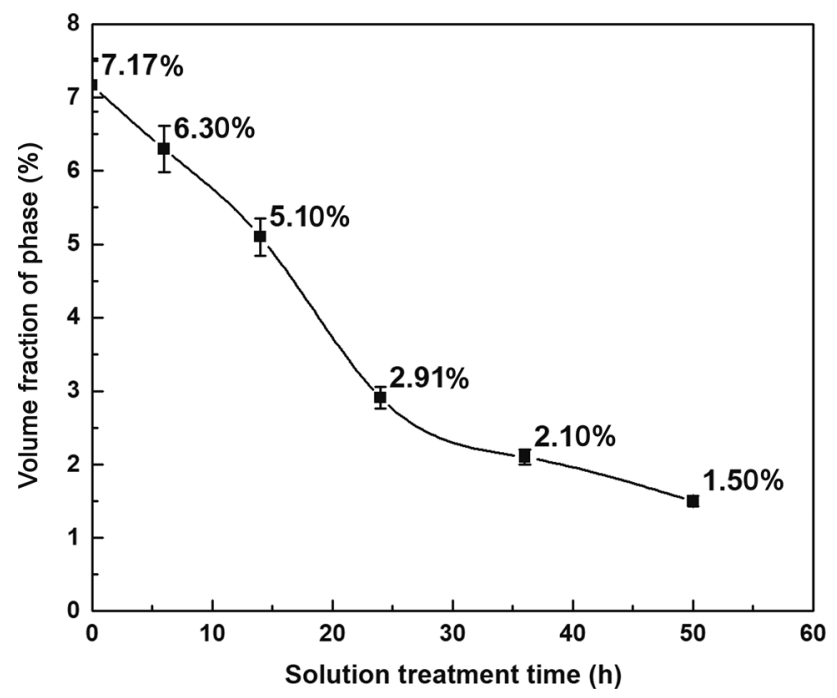

Fig. 6 Volume fraction of intermetallic compounds as a function of solution time the grain boundaries in the as-cast state. They also reported that this phase is sherardized after solution treatment. Considering the morphology of the phases, both I- and $\mathrm{W}$-phases were distinguished in the as-cast and heat-treated specimens as demonstrated in Fig. 9, and their volume fraction and variations were calculated. The results indicate that the amount of I-phase decreased from $5.22 \%$ in the ascast to 3.21 and $0.83 \%$ in the 14 and $36 \mathrm{~h}$ solution-treated specimens, respectively.

In contrast, the percentage of $\mathrm{W}$-phase in the as-cast alloy, $1.90 \%$, increased to $2.04 \%$ after heating for $14 \mathrm{~h}$ and then decreased to $1.28 \%$ after heating for $36 \mathrm{~h}$. It is worth noting that the indirect effect of these two phenomena is more evident in mechanical and corrosion behavior of this alloy. 

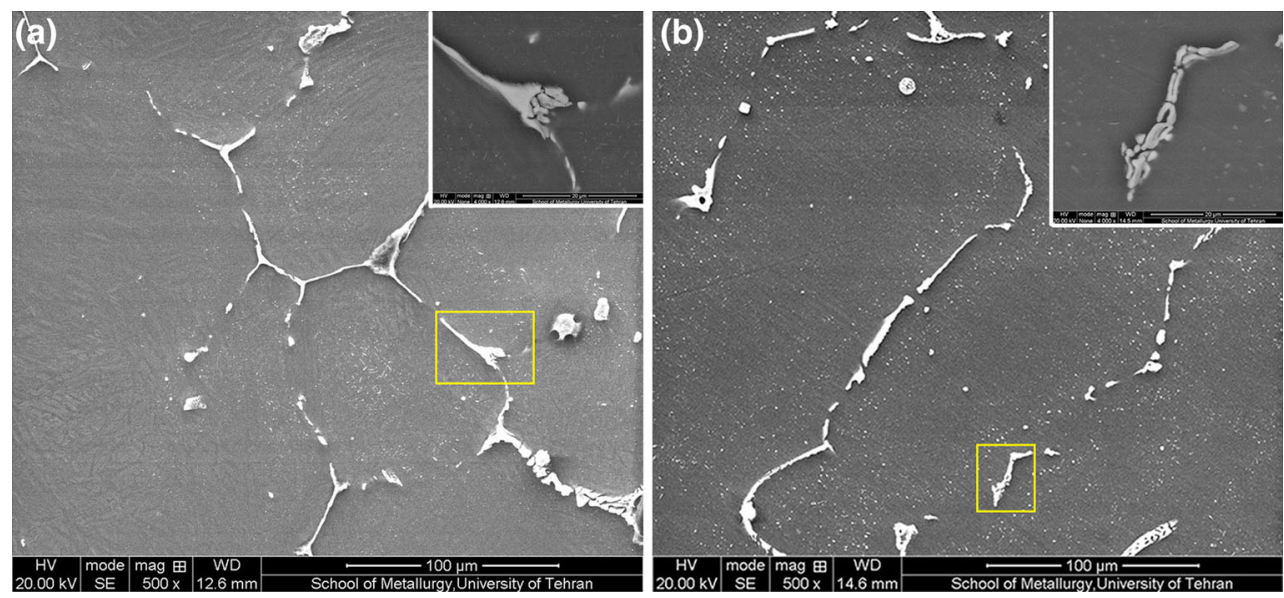

Fig. 7 SEM micrographs of alloys after heat treatment for $14 \mathrm{~h} \mathbf{a}, 36 \mathrm{~h} \mathbf{b}$
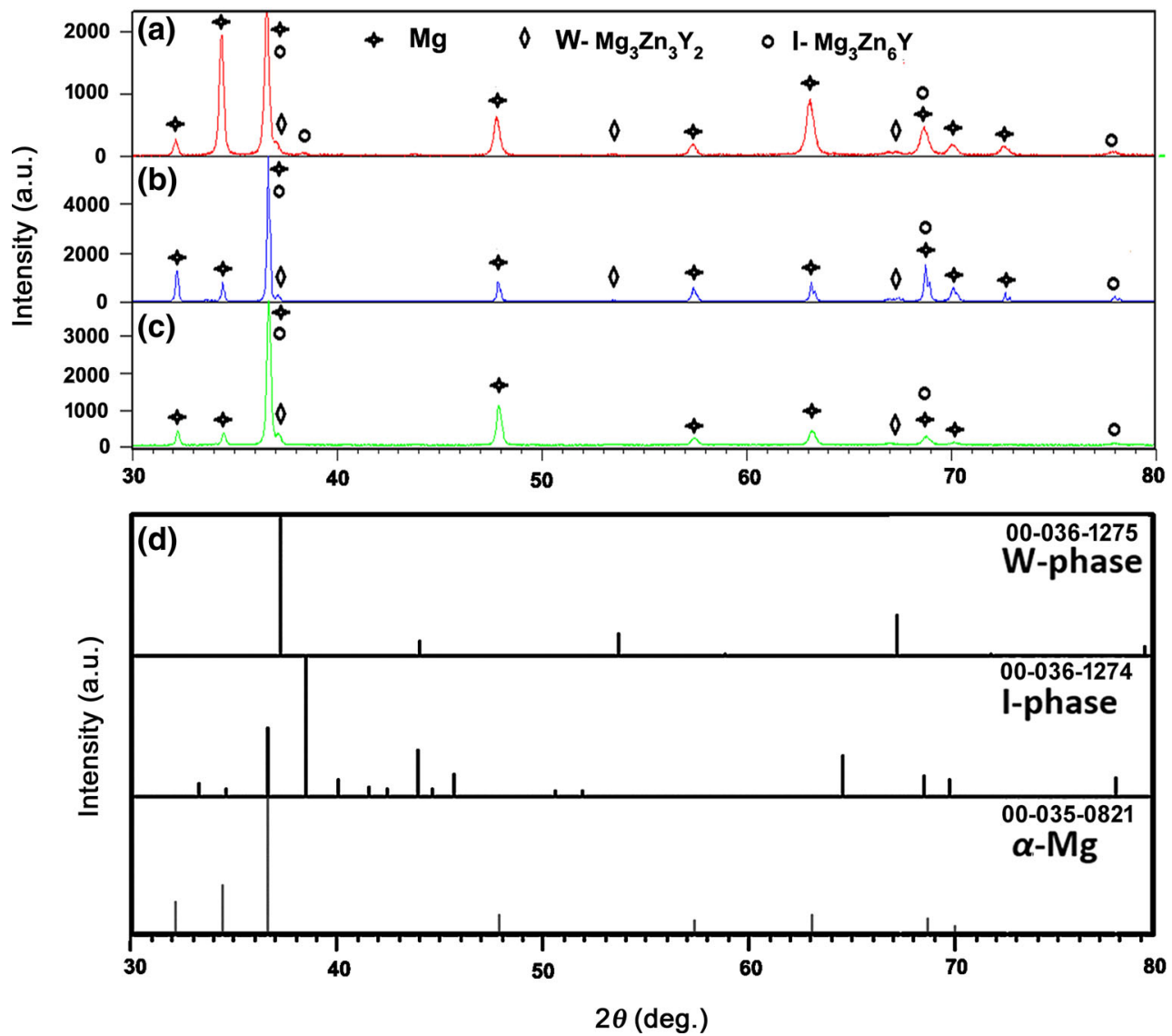

Fig. 8 XRD patterns of as-cast alloy a, specimens after heat treatment for $14 \mathrm{~h} \mathbf{b}, 36 \mathrm{~h} \mathbf{c}$, JCPDS cards corresponding to $\alpha$-Mg, I- and W-phases d

\subsection{Mechanical Properties}

\subsubsection{Tensile Test}

Results of tensile strength tests of the as-cast and solutiontreated specimens are summarized in Fig. 10. It indicates that the yield strength (YS) and ultimate tensile strength
(UTS) of the as-cast specimen are 62.8 and $114 \mathrm{MPa}$, respectively. The strengths are increased to 83.6 and $145 \mathrm{MPa}$, respectively, by increasing the duration of longterm solution treatment to $14 \mathrm{~h}$. The cause of this phenomenon can be attributed to the uniform distribution of the intermetallic phases after the heating. 

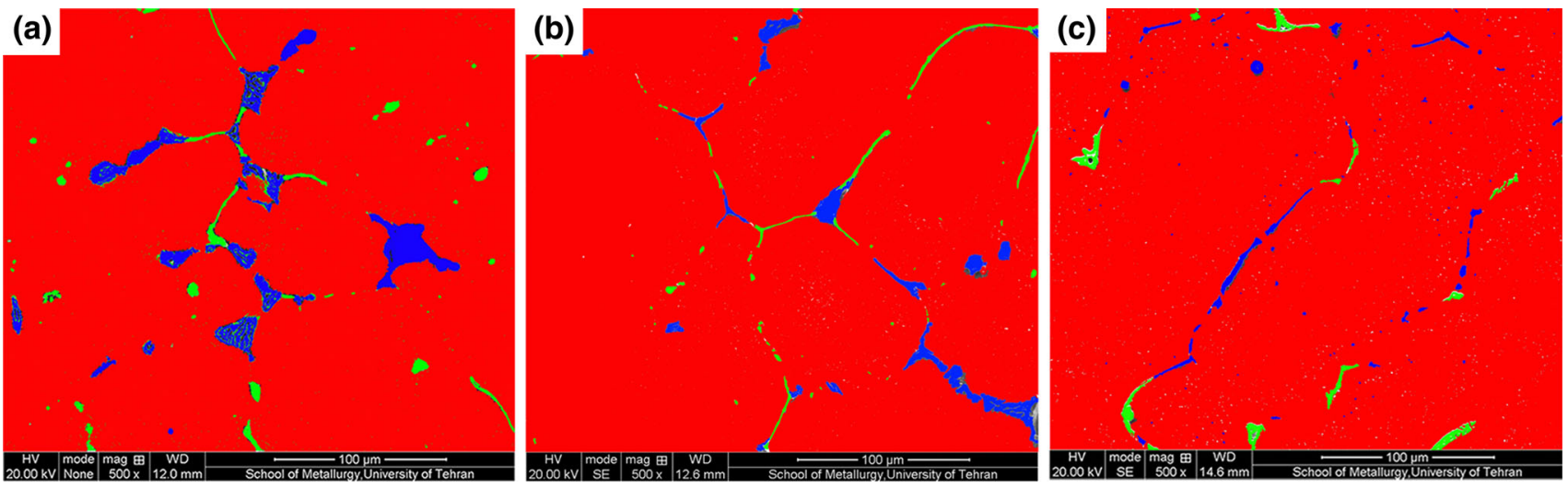

Fig. 9 Morphologies of as-cast alloy a, specimen after heat treatment for $14 \mathrm{~h} \mathbf{b}, 36 \mathrm{~h} \mathbf{c}$ used for calculating I- and W-phases (Red regions: $\alpha$ $\mathrm{Mg}$, green regions: W-phase, blue regions: I-phase)

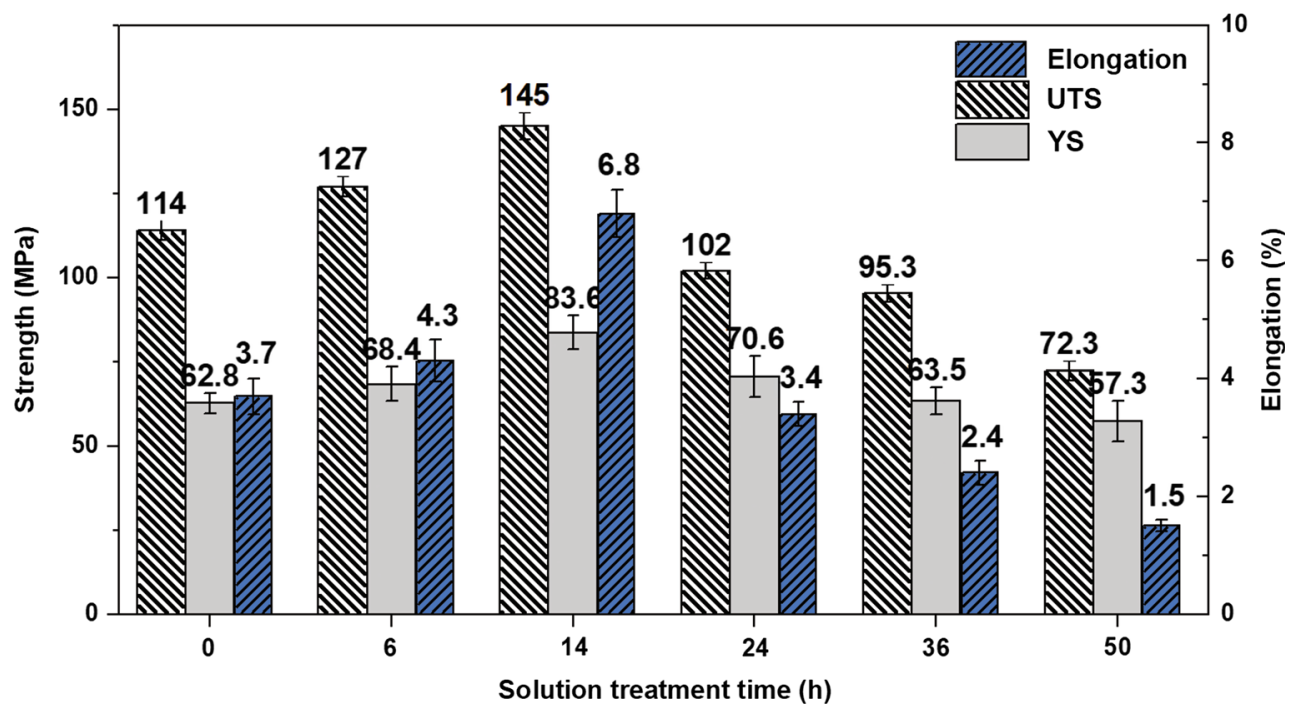

Fig. 10 YS, UTS, and elongation (EL) of experimental specimens

It is worth noting that this period of heating brings about the highest UTS among the investigated durations. In other words, descending trend in YS is observed in the specimens subjected to the longer solution treatment, so the sample treated for $50 \mathrm{~h}$ is characterized with 57.3 and $72.3 \mathrm{MPa}$ for the YS and UTS, respectively. Two reasons can be addressed for this phenomenon.

First, the main strengthening mechanism in this alloy is the formation of solid solution or the function of Orowan mechanism (precipitation of a discontinuous phase) $[34,35]$. Based on the calculations of the total volume fraction of the intermetallic phases (Fig. 6), the specimen solution treated for $14 \mathrm{~h}$ contains higher volume fraction of the intermetallics compared to the specimens experienced longer solution treatment. As a result, this specimen shows more effect of Orowan mechanism in comparison with the others. Consequently, increasing solution time reduces the effect of Orowan strengthening mechanism, leading to reduction in YS and UTS.

The second reason is that the specimen heated for $14 \mathrm{~h}$ contains more amount of I-phase, when compared to the specimens heated for longer durations. In other words, longer solution treatment permits more percentage of I-phase to be transformed into $\mathrm{W}$-phase $[22,23,36]$. It is believed that the presence of eutectic I-phase improves mechanical properties of the alloy [20,37]. In addition, it is worth noting that higher amount of I-phase enhances the elongation of the alloy. This behavior can be ascribed to the prevention of basal dislocation slip by this phase [9], and the reduction in energy at matrix/I-phase interface due to keeping matrix coherency through the creation of ledge and step [15], leading to improvement of interface strength [21]. On the other hand, the presence of intermetallic phases in the matrix of a ductile alloy results in boosting its mechanical properties; however, they lead to stress 
concentration at the interface between the phases and the matrix, causing cracking of matrix/phase interface [38, 39]. In contrast, due to the formation of a coherent interface between the matrix and I-phase, crack nucleation is unlikely possible. Conversely, W-phase with a cubic crystal structure forms a noncoherent interface with $\alpha$-Mg matrix [40, 41], which is prone to crack nucleation, deteriorating mechanical properties, especially elongation [30, 42]. Similar reports have been announced for other cubic phases in magnesium alloys [43]. In summary, long-term solution treatment, which causes more transformation of I-phase into W-phase, reduces YS, UTS, and EL of the alloy. It is worth mentioning that there is a sharp increase in tensile properties of the alloy after $14 \mathrm{~h}$ solution treatment, which is attributed to incomplete phase transformation.

Figure 11 displays SEM images of the fracture surface of the as-cast specimens solution treated for 14 and $36 \mathrm{~h}$. Figure 11a clearly reveals that an intergranular fracture has occurred in the as-cast specimen as a result of the segregations of alloying elements and the formation of brittle intermetallic compounds at the grain boundaries during the casting process. However, it is expected to have alterations in fracture surface due to the microstructure homogenizing through disappearing of as-cast segregation as well as distribution of better intermetallic compounds in the microstructure. Figure 11b, c shows the fracture surface of the specimens solution treated for 14 and $36 \mathrm{~h}$, respectively. The images indicate the occurrence of a mixedmode fracture. In other words, the surfaces represent the presence of some cups and cones or dimples, demonstrating the incidence of ductile fracture. The fracture initiates at micropore at the interface between the intermetallic compounds and the matrix or the grain boundary. Furthermore, there are some regions revealing cleavage planes which suggest brittle fracture has taken place. This may be ascribed to the grain growth, the precipitate solution in the
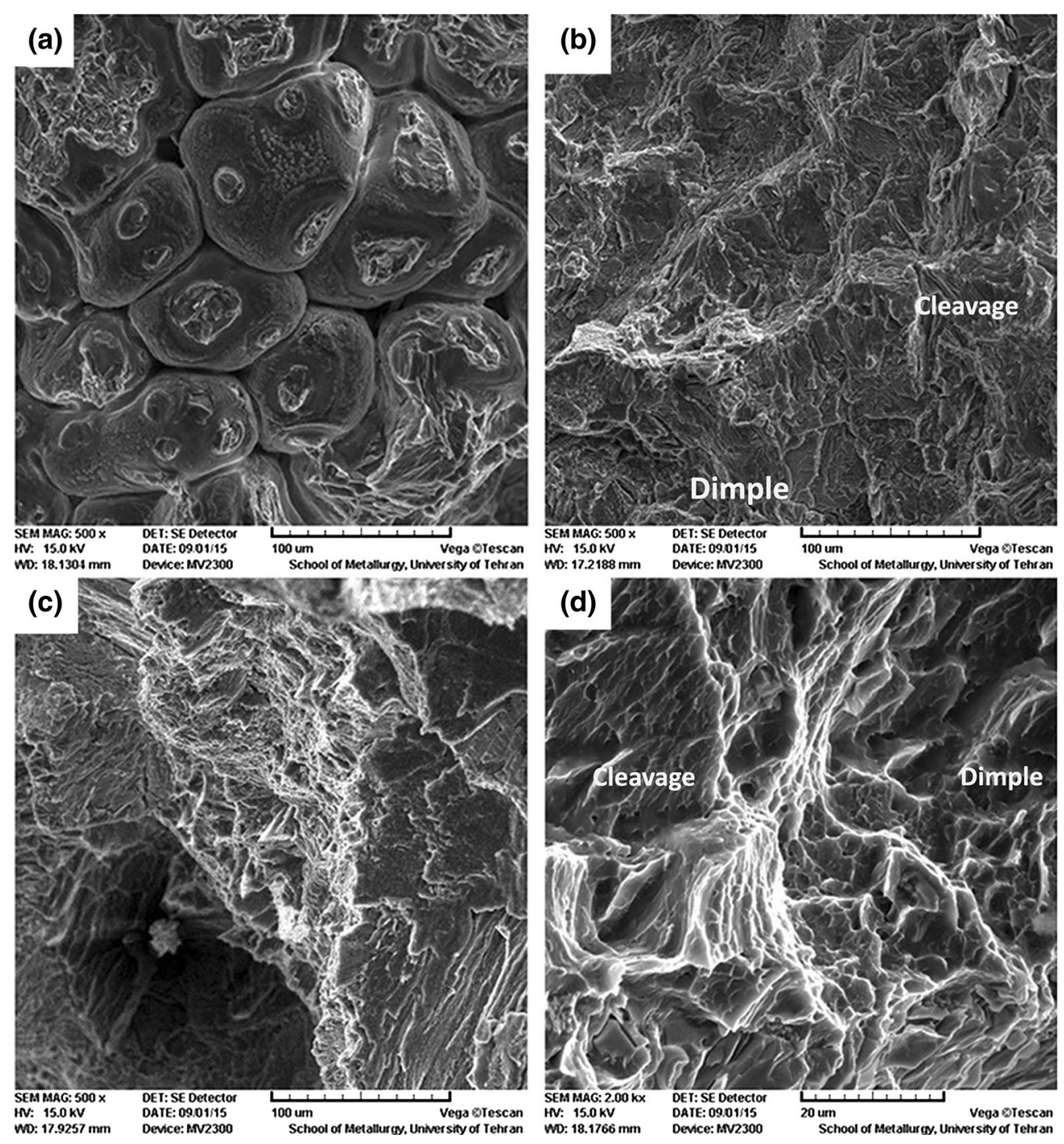

Fig. 11 Fracture surfaces of as-cast alloy a, specimens solution treated for $14 \mathrm{~h} \mathrm{~b}, 36 \mathrm{~h} \mathbf{c}$, higher magnification image of area in $\mathbf{c}$, d 
matrix and phase transformation of I-phase into W-phase, which decreases the nucleation regions for dimples.

In general, as can be inferred from the fracture surfaces, increasing the solution treatment time results in converting the intergranular fracture in the as-cast specimen into mixed-mode fracture in the heat-treated specimens. Figure 11d provides a higher magnification image of the selected square determined at the fracture surface of the specimen solution treated for $36 \mathrm{~h}$ (Fig. 11c), revealing the areas having dimples and cleavages.

\subsubsection{Brinell Hardness Test}

Figure 12 provides the results of Brinell hardness test of the as-cast and solution-treated specimens. It can be observed that the maximum hardness value $(52.06 \mathrm{HB})$ belongs to the specimen solution treated for $14 \mathrm{~h}$, whereas the minimum one $(35.95 \mathrm{HB})$ relates to the $50 \mathrm{~h}$ solutiontreated specimen. The increase in hardness of the specimen solution treatment for duration of up to $14 \mathrm{~h}$ is in agreement with the results of tensile test trend. This is attributed to the incomplete phase transformation that increases the effect of I-phase on hardness improvement.

Further decrease in the hardness of the alloy is obviously referred to the long-term solution treatment, which brings about a considerable amount of intermetallic compounds dissolution in the matrix and decreasing strengthening effect caused by the Orowan mechanism. The grain growth which reduces the obstacles to dislocations movement is another phenomenon in hardness value declining.

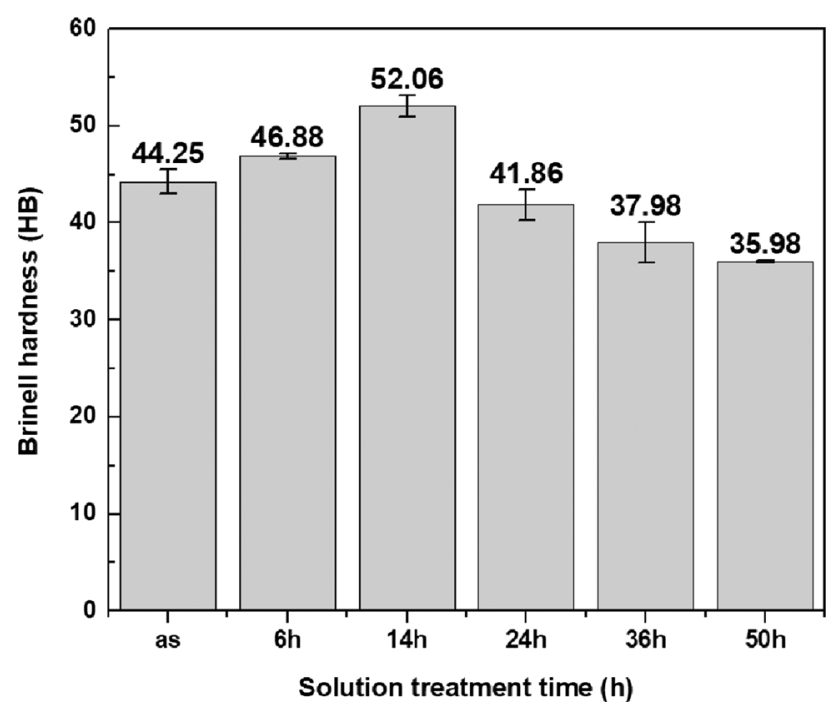

Fig. 12 Brinell hardness of as-cast and solution-treated specimens

\subsection{Corrosion Properties}

\subsubsection{Immersion Test}

The $\mathrm{pH}$ variation and weight loss measurement of the ascast as well as solution-treated specimens are plotted as a function of immersion time in Fig. 13. The difference in $\mathrm{pH}$ of SBF related to the as-cast and the heat-treated specimens can be referred to the amount of intermetallic phases presented as well as dissolved. In general, as the heating treatment prolongs, the amounts of dissolved phases increase accordingly. Consequently, fewer galvanic microcells form between the $\alpha-\mathrm{Mg}$ matrix and the phases, which cause corrosion reactions to occur at a slower rate, resulting in a lower increase in $\mathrm{pH}$ value. This behavior can clearly be seen in the curves shown in Fig. 13a, especially at the first $48 \mathrm{~h}$ of immersion. Although the $\mathrm{pH}$ variation of the SBF behaves similar to a remarkable elevation for all specimens, the as-cast specimen resembles higher rate of $\mathrm{pH}$ increment, whereas the heat-treated specimens show lower $\mathrm{pH}$ increments.

Moreover, the specimen subjected to the longest heating duration performs the lowest rate of $\mathrm{pH}$ increment. This behavior is attributed to the release of $\mathrm{OH}^{-}$anion during the corrosion of magnesium. Increasing $\mathrm{OH}^{-}$anion in the solution leads to stabilization of $\mathrm{Mg}(\mathrm{OH})_{2}$ film, which hinders the $\mathrm{pH}$ escalation. $\mathrm{Mg}(\mathrm{OH})_{2}$ film prevents $\mathrm{Mg}^{2+}$ cation penetrating in SBF and protect magnesium against corrosion. It has been reported that the $\mathrm{Mg}_{3}\left(\mathrm{PO}_{4}\right)_{2}$ can be formed on the surface of magnesium at the beginning stage of corrosion [44]. The formation of this product causes less $\mathrm{OH}^{-}$anion to participate in corrosion products, leading to the escalation of $\mathrm{pH}$ throughout the first stages of immersion. As a result, $\mathrm{OH}^{-}$anion accumulates in the region and $\mathrm{Mg}_{3}\left(\mathrm{PO}_{4}\right)_{2}$ would less likely form, inferring uptrend of $\mathrm{pH}$ alterations [27, 45]. The results of weight loss measurement provided in Fig. 13b indicate that the long-term solution treatment improves the corrosion resistance of the as-cast alloy. In addition, increase in the solution time results in a decreased rate of weight loss, suggesting higher corrosion resistance of the alloy. This behavior, which is attributed to the solution of the I-phase throughout the solution process, is in complete agreement with the results obtained in $\mathrm{pH}$ measurement. According to $\mathrm{He}$ and Yang [27], W-phase has a more positive, while I-phase has a more negative potential compared to the $\alpha-\mathrm{Mg}$ matrix. Therefore, when micro-galvanic cell forms between the matrix and $\mathrm{W}$ - or I-phases in SBF, the matrix will be the anode and corrodes in the former, whereas it will be cathode and I-phase degrades in the latter cell. As a result, dissolving as much as I- phase in $\alpha-\mathrm{Mg}$ diminishes the galvanic microcell regions in the microstructure leading to 

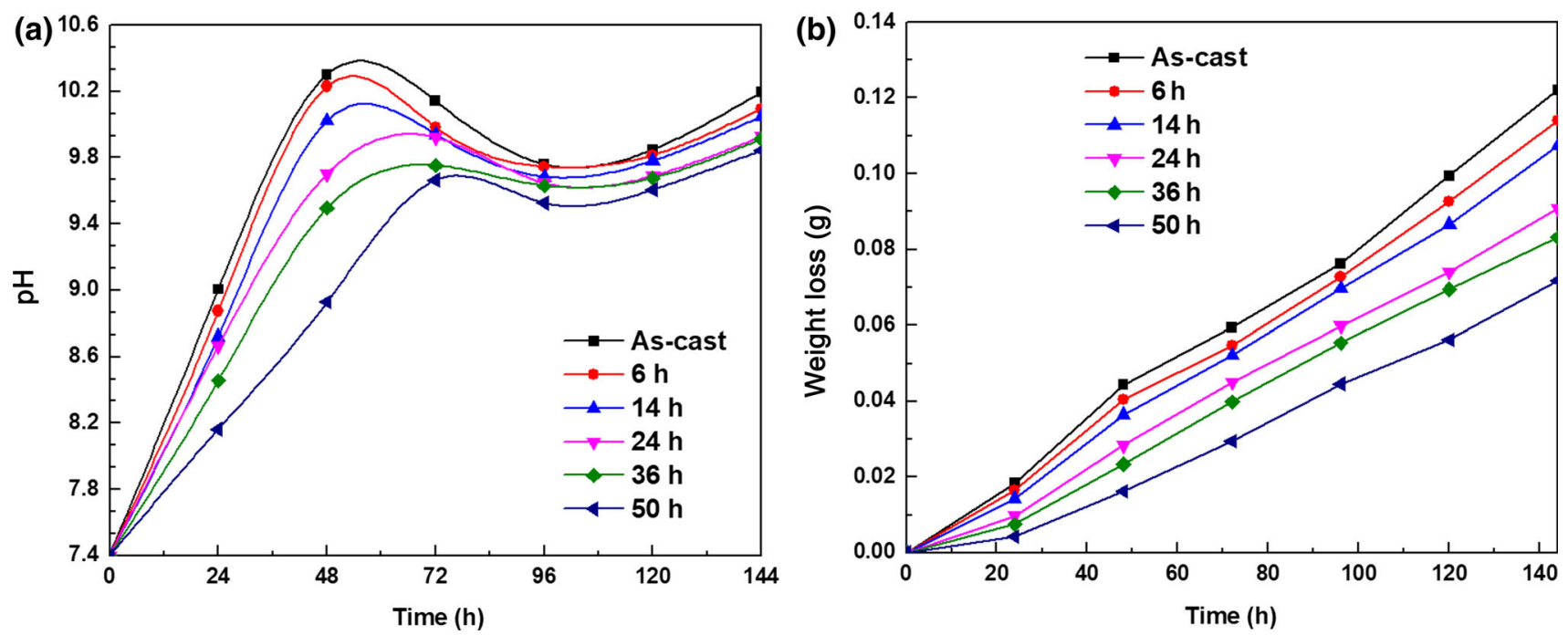

Fig. 13 a pH alteration, b weight loss curves of as-cast and solution-treated specimens after immersion in SBF for $144 \mathrm{~h}$

a lower corrosion of the matrix and corrosion resistance improvement of the alloy. Table 1 shows the amount of weight loss of the as-cast and heat-treated alloy after immersion test in SBF. The results reveal that the as-cast alloy has the highest weight loss among the specimens. For the comparison, the as-cast specimen experienced about 25 and $61 \%$ higher weight loss than that heat treated for 14 and $50 \mathrm{~h}$, respectively.

Figure 14 presents surface morphologies of the as-cast and solution treated for $36 \mathrm{~h}$ specimens after soaking for $144 \mathrm{~h}$ in SBF, as well as typical EDS spectra of corrosion products formed on the surface of alloys. The SEM images (Fig. 14a, b) show the presence of corrosion products, including cracked morphology in dark color and nonuniform particles in white color. It seems that during the first stage of immersion test, $\mathrm{Mg}(\mathrm{OH})_{2}$ film is formed due to the solution of magnesium in SBF. As the time passes and due to the absorption of water from the surrounding environment, the hydrated magnesium hydroxide film is formed. This is the reason when specimens are removed from SBF out, the film experiences shrinkage during drying, leading to the development of cracks in the film [27], which can clearly be observed in Fig. 14. Almost similar behavior was observed in other specimens; however, the amounts of white-colored corrosion products decreased with the

Table 1 Weight loss results of as-cast and solution-treated specimens after immersion test in SBF for $144 \mathrm{~h}$

\begin{tabular}{lllllll}
\hline Specimen & As-cast & \multicolumn{5}{l}{ Solution treatment time (h) } \\
\cline { 3 - 7 } & & 6 & 14 & 24 & 36 & 50 \\
\hline Weight loss (\%) & 5.5 & 5.0 & 4.1 & 3.5 & 3.1 & 2.2 \\
\hline
\end{tabular}

increase in solution treatment period, while the as-cast specimens showed thicker corrosion products. The results are in good agreement with those obtained from the microstructure examinations, thermal analysis, and the calculated phase's amount. In addition, each SEM image provides a magnified image from an area of the surface in which a needle-shaped morphology of the white corrosion products is clearly revealed. In order to access more data concerning the developed corrosion products on the surface, Fig. $14 \mathrm{c}$, d provides the corresponding spectra together with quantitative measurement. Figure $14 \mathrm{c}$ reveals that $\mathrm{Mg}$ and $\mathrm{O}$ elements are the main elements in the dark corrosion product, suggesting the formation of $\mathrm{Mg}(\mathrm{OH})_{2}$ on the surface.

Considering the atomic ratio of oxygen to magnesium, 3.15 , and the presence of $\mathrm{P}$ element, it implies that in addition to $\mathrm{Mg}(\mathrm{OH})_{2}$, other insoluble compound such as $\mathrm{Mg}_{3}(\mathrm{PO} 4)_{2}$ [46] is also developed on the surface of the specimens. It is worth noting that when the $\mathrm{Mg}(\mathrm{OH})_{2}$ layer is thoroughly and coherently developed on the surface, it enables the alloy to be protected against corrosion. However, Jafari et al. [26] reported that chloride anion in SBF attacks the layer, forming pits on it and facilitates the condition for nucleation and growth of hydroxyapatite (HA) due to the presence of $\mathrm{Mg}^{2+}$ and $\mathrm{Ca}^{2+}$ in the media. Figure $14 \mathrm{~d}$, corresponding to the white particles, indicates that besides $\mathrm{Mg}$ and $\mathrm{O}, \mathrm{P}$ and $\mathrm{C}$ are present in the particles. The formation of $\operatorname{Mg}(\mathrm{OH})_{2}$ and $\mathrm{HA}$ on the surface may occur. This process continues until the bone-liked needle apatite is eventually developed, as shown in Fig. 14d. HA along with the magnesium phosphate compound such as $\mathrm{Mg}_{3}\left(\mathrm{PO}_{4}\right)_{2}$ is the main constituents of the bone, absorbing $\mathrm{Ca}^{2+}$ from the surrounding media, contributing to facilitate 

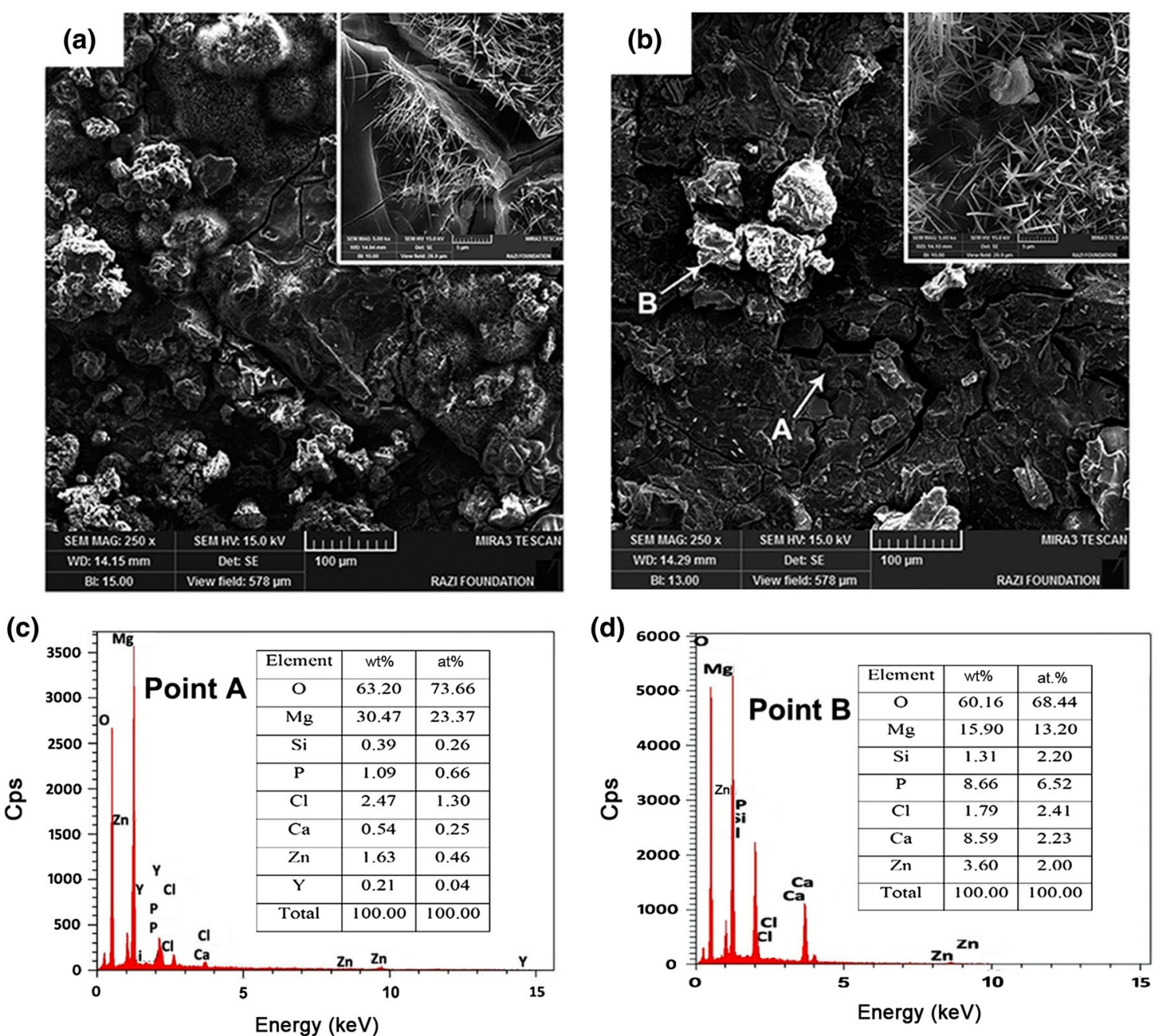

Fig. 14 SEM images of surface of as-cast $\mathbf{a}, 36 \mathrm{~h}$ solution-treated $\mathbf{b}$ specimens after immersion test and EDS analysis of points A $\mathbf{c}, \mathrm{B} \mathbf{d}$ in $\mathbf{b}$

and accelerate the formation of bone cells in the affected area [47].

\subsubsection{Polarization Test}

Figure 15 represents the polarization curves of the as-cast and solution-treated specimens. The similarity of the curves suggests that all specimens behave similar electrochemical corrosion mechanism. The electrochemical parameters, including corrosion current density $\left(i_{\text {corr }}\right)$ and corrosion potential $\left(E_{\text {corr }}\right)$, are extracted from the curves and provided in Table 2 . CR of the specimens, calculated using Eq. (1), is also provided. The results indicate that the long-term solution treatment brings about superior corrosion properties compared to the as-cast alloy. In addition, extending the long-term solution treatment shifts the corrosion potential to positive values, which is in good agreement with the results reported by Morteza et al. [45].

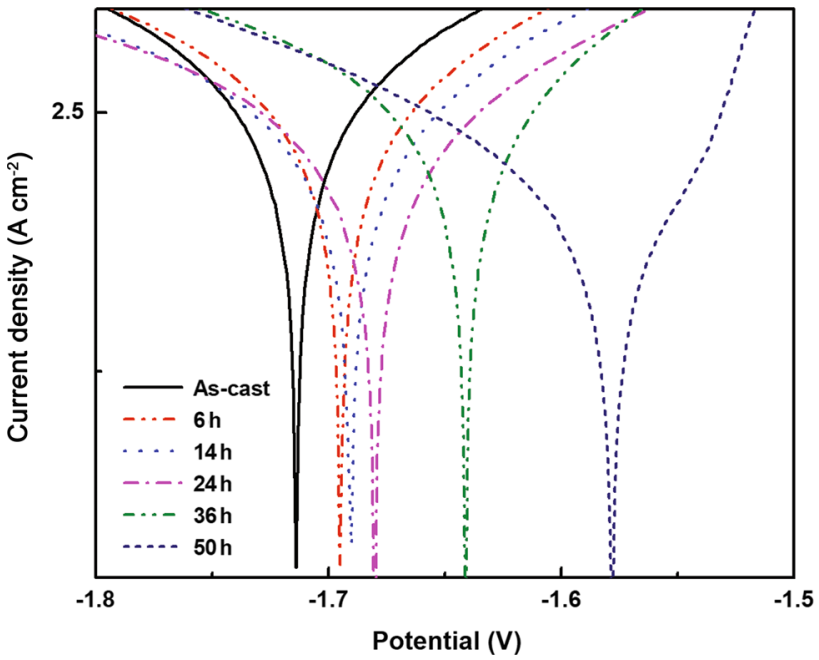

Fig. 15 Polarization curve of as-cast and solution-treated $\mathrm{Mg}-5 \mathrm{Zn}-$ $1.5 \mathrm{Y}$ alloy 
Table 2 Electrochemical parameters extracted from polarization curves of as-cast and solution-treated $\mathrm{Mg}-5 \mathrm{Zn}$ $1.5 \mathrm{Y}$ alloy $\left(\beta_{\mathrm{c}}\right.$ : cathodic Tafel slope, $\beta_{\mathrm{a}}$ : anodic Tafel slope)

\begin{tabular}{llllll}
\hline Specimen & $I_{\text {corr }}\left(\mu \mathrm{A} \mathrm{cm}^{-2}\right)$ & $E_{\text {corr }}(\mathrm{V})$ & $\beta_{\mathrm{a}}\left(\mathrm{V} \mathrm{dec}^{-1}\right)$ & $\beta_{\mathrm{c}}\left(\mathrm{V} \mathrm{dec}^{-1}\right)$ & $\mathrm{CR}\left(\mathrm{mm} \mathrm{y}^{-1}\right)$ \\
\hline As-cast & $223 \pm 8$ & -1.71 & 0.066 & -0.061 & $5.10 \pm 0.18$ \\
$6 \mathrm{~h}$ & $208 \pm 7$ & -1.69 & 0.06 & -0.061 & $4.82 \pm 0.16$ \\
$14 \mathrm{~h}$ & $184 \pm 7$ & -1.67 & 0.059 & -0.062 & $3.93 \pm 0.15$ \\
$24 \mathrm{~h}$ & $149 \pm 7$ & -1.66 & 0.06 & -0.059 & $3.52 \pm 0.15$ \\
$36 \mathrm{~h}$ & $127 \pm 6$ & -1.63 & 0.059 & -0.062 & $2.92 \pm 0.11$ \\
$50 \mathrm{~h}$ & $73 \pm 5$ & -1.58 & 0.050 & -0.062 & $1.87 \pm 0.08$ \\
\hline
\end{tabular}

Furthermore, as Table 2 indicates, lengthening solution time decreases the corrosion current density and consequently reduces the corrosion rate. For instance, the corrosion rate of the alloy dropped from 4.82 to $1.87 \mathrm{~mm} \mathrm{y}^{-1}$ when the solution treatment lengthened from 6 to $50 \mathrm{~h}$, respectively. This behavior in corrosion rate is in agreement with that obtained from the immersion test, which can be ascribed to the more dissolution of I- and W-phases with extending solution treatment time. This leads to the reduction in the micro-galvanic regions, resulting in less corrosion rate.

\section{Conclusions}

In this study, the effect of long-term solution treatment for various periods of time on microstructure, mechanical properties, and corrosion resistance of $\mathrm{Mg}-5 \mathrm{Zn}-1.5 \mathrm{Y}$ alloy was investigated. The results obtained are as follows:

1. Long-term solution treatment reduces volume fraction of all intermetallic phases from $7.17 \%$ in the as-cast alloy to $1.50 \%$ in the alloy solution treated for $50 \mathrm{~h}$. Some volume fractions of I-phase dissolve in the $\alpha-\mathrm{Mg}$ matrix, and some transform into $\mathrm{W}$-phase, and ultimately a few amounts remain in the microstructure.

2. During long-term solution treatment, the tensile strength and elongation of the alloy are improved from $114 \mathrm{MPa}$ and $2.3 \%$ to $131.4 \mathrm{MPa}$ and $5.0 \%$, respectively, by increasing solution time up to $14 \mathrm{~h}$. However, extending solution treatment from 14 to $50 \mathrm{~h}$ deteriorates both properties. The results obtained from hardness test almost follow a similar trend, so that with increasing solution time, both properties show a downtrend. This phenomenon is attributed to the reduction in volume fraction of all precipitates as well as the transformation of some amounts of I-phase into W-phase.

3. Long-term solution treatment improves corrosion resistance, due to the dissolution of intermetallic phases, and consequently, the reduction in galvanic microcells formed between the phases and $\alpha-\mathrm{Mg}$ matrix considerably enhances the corrosion resistance of the alloy. The corrosion rate is decreased from $5.10 \mathrm{~mm} \mathrm{y}^{-1}$ in the as-cast condition to $1.87 \mathrm{~mm} \mathrm{y}^{-1}$, showing over three times improvement, when the alloy is solution treated for $50 \mathrm{~h}$.

4. The optimum time for the long-term solution treatment is $14 \mathrm{~h}$, which has a significant improvement in the mechanical properties as well as corrosion behavior. This long-term treatment can be a novel treatment for production of biodegradable implants.

Acknowledgements The authors are thankful to Shahid Rajaee Teacher Training University for providing the research facilities.

\section{References}

[1] D. Landgrebe, Acta Metall. Sin. (Engl. Lett.) 28, 1496 (2015)

[2] Z.M. Zhang, C.J. Xu, X.F. Guo, Acta Metall. Sin. (Engl. Lett.) 21, 37 (2008)

[3] X.B. Zhang, Y.J. Xue, Z.Z. Wang, Trans. Nonferrous Met. Soc. China 22, 2343 (2012)

[4] N. Li, Y. Zheng, J. Mater. Sci. Technol. 29, 489 (2013)

[5] S. Asqardoust, A.Z. Hanzaki, H.R. Abedi, T. Krajnak, P. Minárik, Mater. Sci. Eng. A 698, 218 (2017)

[6] G. Garcés, M. Maeso, I. Todd, P. Pérez, P. Adeva, J. Alloys Compd. 432, 10 (2007)

[7] Y.M. Zhu, A.J. Morton, J.F. Nie, Acta Mater. 60, 6562 (2012)

[8] E. Zhang, W. He, H. Du, K. Yang, Mater. Sci. Eng. A 488, 102 (2008)

[9] D.K. Xu, W.N. Tang, L. Liu, Y.B. Xu, E.H. Han, J. Alloys Compd. 432, 129 (2007)

[10] D.K. Xu, L. Liu, Y.B. Xu, E.H. Han, J. Alloys Compd. 426, 155 (2006)

[11] D.Q. Wan, G.C. Yang, M. Zhu, Acta Metall. Sin. (Engl. Lett.) 20, 429 (2007)

[12] Y. Xu, D. Xu, X. Shao, E. Han, Acta Metall. Sin. (Engl. Lett.) 26, 217 (2013)

[13] N. Tahreen, D.F. Zhang, F.S. Pan, X.Q. Jiang, C. Li, D.Y. Li, D.L. Chen, J. Alloys Compd. 615, 424 (2014)

[14] D.K. Xu, E.H. Han, Prog. Nat. Sci. Mater. Int. 22, 364 (2012)

[15] D.K. Xu, L. Liu, Y.B. Xu, E.H. Han, Mater. Sci. Eng. A 443, 248 (2007)

[16] K. Yang, J. Zhang, X. Zong, W. Liu, C. Xu, Acta Metall. Sin. (Engl. Lett.) 30, 464 (2016)

[17] A. Singh, M. Watanabe, A. Kato, A.P. Tsai, Mater. Sci. Eng. A 385, 382 (2004)

[18] A. Singh, M. Watanabe, A. Kato, A.P. Tsai, Acta Mater. 53, 4733 (2005)

[19] J.B. Ok, I.J. Kim, S. Yi, W.T. Kim, D.H. Kim, Philos. Mag. 83, 2359 (2003) 
[20] J.Y. Lee, H.K. Lim, D.H. Kim, W.T. Kim, D.H. Kim, Mater. Sci. Eng. A 491, 349 (2008)

[21] D.H. Bae, S.H. Kim, D.H. Kim, W.T. Kim, Acta Mater. 50, 2343 (2002)

[22] J.F. Liu, Z.Q. Yang, H.Q. Ye, J. Alloys Compd. 621, 179 (2015)

[23] A. Singh, H. Somekawa, T. Mukai, Mater. Sci. Eng. A 528, 6647 (2011)

[24] X. Zhang, K. Zhang, X. Deng, H. Li, Y. Li, Prog. Nat. Sci. Mater. Int. 22, 169 (2012)

[25] W. He, E. Zhang, K. Yang, Mater. Sci. Eng. C 30, 167 (2010)

[26] H. Jafari, F. Rahimi, Z. Sheikhsofla, Mater. Corros. 67, 396 (2015)

[27] W. He, K. Yang, Adv. Mater. Res. 101, 2227 (2010)

[28] X. Zong, D. Wang, W. Liu, K. Nie, C. Xu, J. Zhang, Acta Metall. Sin. (Engl. Lett.) 29, 32 (2016)

[29] J.Y. Lee, D.H. Kim, H.K. Lim, D.H. Kim, Mater. Lett. 59, 3801 (2005)

[30] D.K. Xu, W.N. Tang, L. Liu, Y.B. Xu, E.H. Han, J. Alloys Compd. 461, 248 (2008)

[31] X. Chen, L. Liu, J. Liu, F. Pan, Mater. Des. 65, 360 (2015)

[32] Y. Zhang, X. Zeng, L. Liu, C. Lu, H. Zhou, Q. Li, Y. Zhu, Mater. Sci. Eng. A 373, 320 (2004)

[33] X. Fang, S. Wu, S. Lu, J. Wang, X. Yang, Mater. Sci. Eng. A 679, 372 (2017)

[34] X. Zeng, Y. Zhang, C. Lu, W. Ding, Y. Wang, Y. Zhu, J. Alloys Compd. 395, 213 (2005)
[35] T. Mohri, M. Mabuchi, N. Saito, M. Nakamura, Mater. Sci. Eng. A 257, 287 (1998)

[36] A. Singh, A.P. Tsai, Scr. Mater. 49, 143 (2003)

[37] A. Singh, Y. Osawa, H. Somekawa, T. Mukai, C.J. Parrish, D.S. Shih, Metall. Mater. Trans. A 45, 3232 (2014)

[38] Y. Brechet, J.D. Embury, S. Tao, L. Luo, Acta Metall. Mater. 39, 1781 (1991)

[39] D.J. Lloyd, Acta. Met. Mater. 39, 59 (1991)

[40] Z.P. Luo, S.Q. Zhang, J. Mater. Sci. Lett. 12, 1490 (1993)

[41] H.S. Jiang, X.G. Qiao, C. Xu, M.Y. Zheng, K. Wu, S. Kamado, Mater. Des. 108, 391 (2016)

[42] H. Feng, H. Liu, H. Cao, Y. Yang, Y. Xu, J. Guan, Mater. Sci. Eng. A 639, 1 (2015)

[43] J.L. Li, Acta Metall. Sin. (Engl. Lett.) (2017). https://doi.org/10. 1007/s40195-017-0591-6

[44] I. Nakatsugawa, S. Kamado, Y. Kojima, R. Ninomiya, K. Kubota, in Proceedings of the Third International Magnesium Conference, (Institute of Materials, Manchester, 1996), p. 687

[45] S. Morteza, G. Shahri, M.H. Idris, Trans. Nonferrous Met. Soc. China 25, 1490 (2015)

[46] S.E. Harandi, M. Mirshahi, S. Koleini, M.H. Idris, H. Jafari, M.R.A. Kadir, Mater. Res. 16, 11 (2013)

[47] J. Wang, Y. Li, S. Huang, Y. Wei, X. Xi, K. Cai, F. Pan, J. Mater. Sci. Technol. 30, 1255 (2014) 